\title{
On the Relationship between Warranty and the Risk of Information Asymmetry*
}

\author{
Dimitar Christozov \\ American University in Bulgaria, Blagoevgrad, Bulgaria \\ dgc@aubg.bg \\ Stefanka Chukova \\ Victoria University of Wellington, Wellington, New Zealand \\ Stefanka.Chukova@vuw.ac.nz \\ Plamen Mateev, \\ University of Sofia "St. Kliment Ohridski”, Sofia, Bulgaria \\ pmat@fmi.uni-sofia.bg
}

*This research is partially supported by NFSI-BG, Grant No VU-MI-105/2005

\begin{abstract}
Nowadays the product warranty is considered to be a valuable attribute of the product. It is a tool to enforce the competing power of the producer on the market place. There are two types of problems the product warranty addresses. Firstly, warranty deals with the malfunctioning of the product and, secondly, it addresses the information asymmetry, i.e., the misunderstanding and misinterpretation of the features and qualities of the product. The second aspect is of great importance in the light of indirect business communication, as in e-commerce. The aim of this paper is quantifying the risk of misunderstanding caused by information asymmetry and defining an appropriate product warranty policy, which depends on this risk.
\end{abstract}

Keywords: information asymmetry, misinforming, warranty, risk.

\section{Introduction}

The phenomenon of information asymmetry between two parties is observed quite often in our everyday life. It occurs when one of the parties has better understanding, possesses deeper knowledge and is better informed on the subject of communication than the other one. For example, a car dealer is an expert on the performance of his products and has available complete information on all features and qualities of the product, such as, reliability and performance parameters, war-

Material published as part of this publication, either on-line or in print, is copyrighted by the Informing Science Institute. Permission to make digital or paper copy of part or all of these works for personal or classroom use is granted without fee provided that the copies are not made or distributed for profit or commercial advantage AND that copies 1) bear this notice in full and 2) give the full citation on the first page. It is permissible to abstract these works so long as credit is given. To copy in all other cases or to republish or to post on a server or to redistribute to lists requires specific permission and payment of a fee. Contact Publisher@InformingScience.org to request redistribution permission. ranty contract etc. On the other hand, an average customer might be well informed about the product he is interested in buying, but his overall knowledge of the auto products is, generally, limited compare to the knowledge of her counterparty in the sale/purchase process.

There are several aspects of information asymmetry that have attracted the inter- 
est of researchers. Next, we list a few of the different research aspects related to the information asymmetry.

1) The concept of information misbalance originates in Arrow (1963), who introduced it as a "moral hazard". His ideas were further developed by Akerlof (1970) in his famous paper "The Market for 'Lemon's", where the term "Information Asymmetry" was used for the first time. Akerlof investigated the influence of asymmetric information on the market value of a commodity. He pointed out that for a market with asymmetric information, the value of a commodity tends to go down, even for a commodity with perfect quality. Many researchers, especially interested in financial markets, continue this line of investigations.

2) Studies related to the asymmetric impact of negative and positive information on the social trust, known as principle of Information Asymmetry or Trust Asymmetry, initiated by Slovac (1993), is still an active area of research (White \& Eiser, 2005).

3) The impact and usage of the information asymmetry to improve the influence in business relationships is yet another area of research, which has attracted the attention of many researchers. This area of research branched off from the studies initiated by Akerlof.

4) To the best of our knowledge, the role of information asymmetry as a source of misinterpretation, which results in misinforming and/or misleading in a sales/purchase process and might lead to wrong purchase decisions has never been studied at the level it deserves. Some authors (see Chang et al. 2006) consider the impact of information asymmetry on the success in business transactions, but they do not go beyond recommendations of how to improve the information process. Christozov, Chukova, and Mateev (2006) proposed a model to quantify the risk of misinforming, caused by information asymmetry and the current paper extends their study further by:

a. updating and extending the model used in measuring the risk of misinforming;

b. investigating the role of different types of warranty policy on purchasing decisions under information asymmetry;

c. proposing a stratification of the group of customers according to two factors. The first one is the customer's attitude towards the product. The second factor is the preference of the customers regarding the type of the product warranty. Based on these two factors we determine subgroups of customers and study their risk of misinforming;

d. assessing the relationship between risk of misunderstanding and warranty;

e. providing recommendations to the producer on the product warranty, based on the risk of misinforming.

The outline of this paper is as follows. The first section provides the description of the model for quantifying and evaluating the risk of misinforming. The second section discusses the relationship between risk of misinforming and warranty. In the third section, we provide an illustrative example. Section 4 concludes with a few ideas for further research.

\section{Quantitative Measure of the Risk of Misinforming}

Next, we propose a model to quantify the risk of misinforming, which is an extension of Christozov, Chukova and Mateev (2006) study. 
We introduce the following notation and assumptions:

1. One of the main difficulties in quantifying the risk of misinforming is that the risk is subjective, i.e., one and the same message containing information on the product of interest, may convey correct information to some customers and misinform others. This misinformation can have different degrees and consequences for the individual customers within a given group of customers. Thus, in one hand, in order to evaluate the risk of information asymmetry of a group of customers, we need to take into account each individual reaction to the message, and the risk of the group will be the compound result of these individual reactions. On the other hand, stratifying the group into subgroups and investigating the risk at subgroup level could gain an additional insight regarding the level of risk.

2. A message describing the product may inform some of the customers correctly regarding several properties or features of the product, as well as abilities of the product to solve for a particular task or category of tasks, and at the same time, it can misinform them regarding some other features or tasks. Our model aims to allow measuring the risk of misinforming at the task level.

3. In order to simplify the model, we will model only the risk of misinforming between a single producer/seller to a group of customers/buyers regarding a single product. We denote the product by $\mathrm{D}$.

In order to quantify the risk of misinforming, caused by the information asymmetry, we need to identify and measure the factors, which influence this risk

\section{Description of the Group of Buyers (Customers) and Group of Tasks}

\section{Description of the group of buyers (customers)}

The group of buyers is denoted by $B=\left\{b_{j}\right\}, j=1,2, \ldots, n$, where $b_{j}$ represents the $j^{\text {th }}$ buyer. Each buyer $j$ has a set of tasks that $\mathrm{s} /$ he needs to solve.

\section{Description of the tasks (problems)}

Let $A_{j}=\left\{a_{i j}\right\}, i=1,2, \ldots, k_{j}$, be the set of the $k_{j}$ tasks of the $j^{\text {th }}$ customer that s/he needs to solve by using product $\mathrm{D}$. Assume that for every task $a_{i j}$, the buyer $j$ has a degree of acceptance of the product with respect to this task, say $q_{i j}$. The degree of acceptance of the product $q_{i j}$ is a measure of the buyer's opinion regarding the minimal quality the product $\mathrm{D}$ has to have in order to be suitable to solve this task. It is described in terms of quality of the product, and it has to be converted to a number $0 \leq q_{i j} \leq 1$, to allow for further usage. If every product is acceptable than $q_{i j}=$ 0 , whereas if $q_{i j}=1$, the buyer has the highest expectations on the quality of the product regarding this particular task. An interesting question is how to evaluate the degree of acceptance $q_{i j}$. There are two options:

- If only a single feature of the product $\mathrm{D}$ is relevant to this quality, $q_{i j}$ may be normalized by using

$$
\hat{q}_{i j}=\left(q_{i j}-q_{o}\right) /\left(q_{\max }-q_{0}\right),
$$

where $q_{0}$ is the default quality that every product intended to solve for this task should have, and $q_{\max }$ is the highest quality of a product, which is intended to solve this task, can achieve. 
- The problem of normalizing the degree of acceptance may be further complicated if there is a set of properties, instead of a single property, that identifies the quality of the product essential for solving of this particular task. In this case, the Integral Quality Indicator approach (see Christozov, 1997) can be used.

Because $\hat{q}_{i j}$ is subjective, it is still an open problem how to estimate it. In this study, we will use $q_{i j}$, instead of $\hat{q}_{i j}$, and we will assume that $q_{i j}$ is known and has been already normalized as a number between 0 and 1 .

The set of all tasks $\mathrm{A}=\left\{\mathrm{UA}_{\mathrm{j}}\right\}, \mathrm{j}=1,2, \ldots, \mathrm{n}$, can be structured according to the existence of tasks that are common for many, not necessarily all, buyers. Each common task specifies a particular category within the set of tasks $A$. Let $A_{i}^{*}, i=1,2, \ldots, k$ denote the $i^{\text {th }}$ category of tasks for the set of buyers $B$. Table 1 represents the structure of the set of tasks. The rows of the table represent the tasks, according to buyers, while the columns show the tasks according to the tasks category. We assume that there are tasks common for all buyers, e.g., surfing the Internet. Different buyers have different needs with respect to this task and different degree of acceptance. For example, some buyers will use Internet to download movies and other large files; others will use Internet only for shopping, which does not require transferring of large data sets, etc. The "Internet surfing" is a category and "downloading movies" is a specific task from this category. And of course, different buyers have different measures of what is acceptable performance in using Internet. For completeness, we will assume that all buyers have all tasks, but for some of these tasks the buyer's need is equal to zero.

Table 1. Representation of the set of tasks

\begin{tabular}{|c|c|c|c|c|c|c|c|}
\hline \multicolumn{2}{|c|}{} & $A_{1}^{*}$ & $A_{2}^{*}$ & $\cdots$ & $A_{i}^{*}$ & $\cdots$ & $A_{k}^{*}$ \\
\hline $\mathrm{B}_{1}$ & $\mathrm{~A}_{1}$ & $a_{11}$ & $a_{21}$ & $\cdots$ & $a_{i 1}$ & $\cdots$ & $a_{k 1}$ \\
\hline $\mathrm{B}_{2}$ & $\mathrm{~A}_{2}$ & $a_{12}$ & $a_{22}$ & $\cdots$ & $a_{i 2}$ & $\cdots$ & $a_{k 2}$ \\
\hline$\cdots$ & $\cdots$ & & & & & & \\
\hline $\mathrm{B}_{\mathrm{j}}$ & $\mathrm{A}_{\mathrm{j}}$ & $a_{1 j}$ & $a_{2 j}$ & $\cdots$ & $a_{i j}$ & $\cdots$ & $a_{k j}$ \\
\hline$\cdots$ & $\cdots$ & & & & & & \\
\hline $\mathrm{B}_{\mathrm{n}}$ & $\mathrm{A}_{\mathrm{n}}$ & $a_{1 n}$ & $a_{2 n}$ & $\cdots$ & $a_{i n}$ & $\cdots$ & $a_{k n}$ \\
\hline
\end{tabular}

Note that some of the tasks the buyer needs to solve using the product may not be among the tasks the product is design for. Therefore, the probability that the product is suitable to solve for such tasks is assumed to be equal to zero.

Then, $A^{*}=\bigcup_{i=1}^{k} A_{i}^{*}$ is the set of all different tasks and, of course, $A^{*}=A$. Set $A$ describes the set of tasks as a union of buyers' tasks, whereas $A^{*}$ is the same set from task category point of view.

\section{The need of a buyer to solve for a task}

Assume that, the need of the $j^{t h}$ buyer to solve for a task from category $A_{i}{ }^{*}$ is $n_{i j}$, where $0 \leq n_{i j} \leq 1$. If $n_{i j}=0$, this means that the $j^{\text {th }}$ buyer does not need to solve for task $A_{i}{ }^{*}$, while $n_{i j}=1$ means that 
s/he definitely needs to solve for it. We can assume that if $n_{i j}=0$, then $q_{i j}=0$, i.e., if the buyer $j$ does not need to solve the task $A_{i}{ }^{*}$, then every product is $100 \%$ acceptable for him. Therefore, the $j^{t h}$ buyer can be described by the triple $b_{j}=\left\{\left(a_{i j}, q_{i j}, n_{i j}\right) \mid a_{i j} \in A_{i}{ }^{*}, i=1,2, \ldots, k, 0 \leq n_{i j}, q_{i j}, \leq 1\right)$. We will assume that for every buyer $j$ all problems in $A^{*}$ are presented in his description, but for some of the problems the corresponding need is equal to zero.

\section{Description of the Seller}

Next, we focus on the description of the Seller as a party in the communication process. The Seller sells the product $\mathbf{D}$, which is capable of solving tasks from $A_{i}{ }^{*}$. Let $p_{i}=p\left(A_{i}{ }^{*}\right)$ be the probability that $\mathbf{D}$ is capable to solve for task $A_{i}{ }^{*}$. If $p\left(A_{i}{ }^{*}\right)=0$, then $\mathbf{D}$ is not suitable at all for solving for this task, whereas, if $p\left(A_{i}{ }^{*}\right)=1, \mathbf{D}$ is an excellent choice for solving for $A_{i}^{*}$, i.e., $\mathbf{D}$ meets any high level of buyer's need, related to the task $A_{i}{ }^{*}$. Further, as a part of his marketing policy, the Seller sends a message to the group of buyers describing the properties/qualities/features of D. The content of this message is based on the sellers' evaluation of $p\left(A_{i}{ }^{*}\right)$ and it does not take into account the value of $\left\{q_{i j}\right\}, j=1,2, \ldots, n$. In this communication, the information asymmetry is due to the difference between the expertise of the seller and the buyer regarding the product $\mathrm{D}$. The usage of a specialized terminology in the message may increase the level of the information asymmetry. Based on this message and his/her background, the buyer $j$ assesses the probability $\hat{p}_{i j}=\hat{p}\left(a_{i j}\right)$ that the product $\mathbf{D}$ will solve for his/her task $a_{i j}$. If $n_{i j}=0$ and/or $q_{i j}=0$, then there is no need to estimate $\hat{p}\left(a_{i j}\right)$.

The $j^{\text {th }}$ buyer makes his/her purchase decision based on the comparison between $\left\{\hat{p}_{i j}\right\}$ and $\left\{q_{i j}\right\}$ over all tasks from his/her set $A_{j}$. Due to the information asymmetry, the values of $p_{i}$ and $\hat{p}_{i j}$ may differ significantly. Also these values may differ because $p_{i}$ is evaluated by the Seller for the category of task $A_{i}{ }^{*}$ and not for the particular $a_{i j} \in A_{i}{ }^{*}$, which is of interest to the $j^{\text {th }}$ buyer.

\section{Measuring the Risk of Misinforming}

Next we introduce a measure of the risk of misinforming, say $r$, with three components - probability of wrong decision $\left(r_{i j}\right)$, level of misunderstanding $\left(\hat{p}_{i j}-p_{i}\right)$ and Buyer's need $\left(n_{i j}\right)$. First we consider the risk $r_{i j}$ of a wrong decision related to one particular task and one buyer, next we extend this measure for the whole set of tasks for one buyer, say $r_{j}^{B}$, and generalize further, for the risk $R$ of the whole set of buyers.

\section{The risk of a wrong decision of a single buyer $j$ with respect to a single task $a_{i j}$}

We have two possible outcomes for the buyer's purchase decision regarding the product D, namely, "YES" (positive, purchase the product) or "NO" (negative, do not purchase the product). The buyer $j$ will make a positive decision if for all $a_{i j} \in A_{j}$, such that $n_{i j}>0$ and $q_{i j}>0$, the inequality $\hat{p}_{i j} \geq q_{i j}$ holds and negative decision if the opposite inequality $\hat{p}_{i j}<q_{i j}$ is valid. The correctness of this decision depends also on the relationship between $p_{i}$, the actual ability of $\mathrm{D}$ to solve for $a_{i j}, \hat{p}_{i j}$ - the estimated ability of $\mathrm{D}$ to solve for $a_{i j}, q_{i j}$ - the degree of acceptance, and $n_{i j}$ - the need to solve for the task $a_{i j}$. Each of the six possible orderings between $p_{i}, \hat{p}_{i j}$ and $q_{i j}$ identify whether buyer's decision to buy the product is wrong or correct with respect to task $a_{i j}$. We use the following notation to indicate the correctness/incorrectness of the buyer's purchase decision with respect to task $a_{i j}$ : 


$$
r_{i j}=\left\{\begin{array}{l}
1 \quad \text { the decision is wrong } \\
0 \quad \text { the decision is correct }
\end{array}\right.
$$

Therefore we have the following six cases:

1. $\quad p_{i}<\hat{p}_{i j}<q_{i j}$ - the product is not suitable to solve for task $a_{i j}$, the customer's estimation of the suitability of the product is optimistic and below the degree of acceptance, thus the decision is negative and correct and $r_{i j}=0$;

2. $\quad p_{i}<q_{i j}<\hat{p}_{i j}$ - the product is not suitable to solve for task $a_{i j}$, the customer's estimation of the suitability of the product is optimistic and above the threshold of acceptance, thus the decision is positive and wrong, and $r_{i j}=1$;

3. $q_{i j}<p_{i}<\hat{p}_{i j}$ - the product is suitable to solve for task $a_{i j}$, the customer's estimation of the suitability of the product is optimistic and above the threshold of acceptance, thus the decision is positive and correct, and $r_{i j}=0$;

4. $\quad \hat{p}_{i j}<p_{i}<q_{i j}$ - the product is not suitable to solve for task $a_{i j}$, the customer's estimation of the suitability of the product is pessimistic and below the threshold of acceptance, thus the decision is again negative and correct, and $r_{i j}=0$;

5. $\quad \hat{p}_{i j}<q_{i j}<p_{i}$ - the product is suitable to solve for task $a_{i j}$, the customer's estimation of the suitability of the product is pessimistic and below the threshold of acceptance, thus the decision is negative and wrong, and $r_{i j}=1$;

6. $\quad q_{i j}<\hat{p}_{i j}<p_{i}$ - the product is suitable to solve for task $a_{i j}$, the customer's estimation of the suitability of the product is pessimistic and above the threshold of acceptance, thus the decision is positive and correct, and $r_{i j}=0$.

The amount of misinforming is represented by the distance between $p_{i}$ and $\hat{p}_{i j}$, but the risk exists, only if the purchasing decision is wrong, i.e., only if $r_{i j}=1$.

We propose two measures of the risk of misunderstanding. The first one is the measure of the adjusted risk, represented by $n_{i j} r_{i j} a b s\left(\hat{p}_{i j}-p_{i}\right)$. This measure accounts for the amount of need that will be satisfied/unsatisfied, adjusted for the level of misinforming. The second measure of the risk, so called unadjusted risk, is represented by $n_{i j} r_{i j}$. It is based on the amount of need that will be satisfied/unsatisfied under right/wrong purchase decision with respect to task $a_{i j .}$. The unadjusted risk does not take into account the level of misinforming.

\section{The risk of misunderstanding of a single buyer}

The overall adjusted risk for the $j^{\text {th }}$ buyer is

$$
r_{j}^{a}=\frac{1}{\sum_{i} n_{i j}} \sum_{i=1}^{k} n_{i j} r_{i j} a b s\left(\hat{p}_{i j}-p_{i}\right), j=1,2, \ldots, n
$$

where the summation is over all categories of tasks $A^{*}$. The overall unadjusted risk for the buyer $j$ is equal to 


$$
r_{j}^{u}=\frac{1}{\sum_{i} n_{i j}} \sum_{i=1}^{k} n_{i j} r_{i j}, j=1,2, \ldots, n
$$

where, again, the summation is over $A^{*}$.

\section{The risk of misunderstanding of the group of buyers}

From Seller's point of view, it is appropriate to measure the risk of misinforming, according to the categories of tasks as well as in general. Depending on the available information about $\hat{p}_{i j}$, $n_{i j}$ and $q_{i j}$, we propose three possible measures of the risk of misinforming from seller's point of view (Table 2):

Table 2. Measures of Risk of Misinforming

\begin{tabular}{|l|l|l|}
\hline \multicolumn{1}{|c|}{ Measure } & \multicolumn{1}{|c|}{ For $i$-category of tasks $\left(A_{i}^{*}\right)$} & \multicolumn{1}{c|}{ General } \\
\hline Simple: & $R_{i}^{s}=\frac{1}{n} \sum_{j=1}^{n} r_{i j}$ & $R^{s}=\frac{1}{k n} \sum_{i=1}^{k} \sum_{j=1}^{n} r_{i j}$ \\
\hline Unadjusted: & $R_{i}^{u}=\frac{1}{\sum_{j} n_{i j}} \sum_{j=1}^{n} n_{i j} r_{i j}$ & $R^{u}=\frac{1}{k} \sum_{i=1}^{k} \frac{1}{\sum_{j} n_{i j}} \sum_{j=1}^{n} n_{i j} r_{i j}$ \\
\hline Adjusted: & $R_{i}^{a}=\frac{1}{\sum_{j} n_{i j}} \sum_{j=1}^{n} n_{i j} r_{i j} a b s\left(\hat{p}_{i j}-p_{i}\right)$ & $R^{a}=\frac{1}{k} \sum_{i=1}^{k} \frac{1}{\sum_{j} n_{i j}} \sum_{j=1}^{n} n_{i j} r_{i j} a b s\left(\hat{p}_{i j}-p_{i}\right)$ \\
\hline
\end{tabular}

\section{Division of the group of buyers}

Finally, the next definition allows us to distinguish between the three categories of buyers: optimists, pessimists and realists.

Definition. For a given positive number $\varepsilon$, we say that the buyer $b_{j}$ is an $\varepsilon$-optimist if $\sum_{i=1}^{k} n_{i j}(\hat{p}-p)>\varepsilon$, or he is an $\varepsilon$-pessimist if $\sum_{i=1}^{k} n_{i j}(\hat{p}-p)<-\varepsilon$ or he is an $\varepsilon$-realist if $-\varepsilon<\sum_{i=1}^{k} n_{i j}(\hat{p}-p)<\varepsilon$

\section{Relationship between Risk and Warranty}

In what follows, we discuss two aspects of the relationship between the risk of misinforming and warranty. Firstly, we look at how the risk of misinforming, caused by information asymmetry is affected by the product warranty offered by the seller. Secondly, we elaborate on the type of information the risk of misinforming provides that can be utilized by the producer in order to improve his marketing policy. 


\section{Assumptions and Definitions}

We based our study on the following assumptions:

1. The two parties, the seller (or producer) and the buyer (or customer), are equally negatively affected by a wrong purchase decision. For a buyer, any wrong purchase decision results in moral and financial disadvantages. On the other hand, for a seller, any wrong purchase decision is also strongly undesirable, because it leads to unsatisfied customers, which can have a negative impact on the producer's reputation and can generate mistrust toward him. According to the Principle of Information Asymmetry (Trust Asymmetry), a disappointed customer may harm the seller's reputation on the marketplace much stronger than a number of satisfied customers can contribute to its improvement.

2. We distinguish between three categories of customers:

a. Optimists are customers, who overestimate the capabilities of the product. They buy the product, even if the product is not suitable to their needs and requirements;

b. Pessimists are customers, who underestimate the capabilities of the product. These customers do not buy the product, even if it is suitable to their needs and requirements.

c. Realists are customers, who estimate the capabilities of the product correctly and buy only if it suits to their needs and requirements.

The harm to the seller's reputation caused by optimists' wrong purchase decision is higher than that caused by the pessimists' wrong purchase decision. In the later, the harm is simply lost of one sale, whereas in the former, the harm comes from spreading negative information about the product, which can have a long-term negative effect on the producer's reputation.

3. The seller identifies two thresholds for the values of the risk, say $R_{l}$ and $R_{h}$, which divide the risk into three categories.

a. Let $0 \leq R \leq R_{l}$. This is the category of low risk, i.e., the risk of misinforming is such that only few customers end up making a wrong purchase decision due to the information asymmetry. The risk is so small that it does not contribute significantly to the overall performance evaluation of the product on the market, i.e., the harm caused by the information asymmetry is acceptable for both parties involved in the sales/purchase process. Hence, the message with the description of the product, used to market the product, is adequate and serves well to attract and convey correct information to the majority of the customers.

b. Let $R_{h} \leq R \leq 1$. This is the category of high risk. The risk of misinforming is such that, the majority of the customers are unsatisfied with their purchase decision, i.e., the impact of the information asymmetry is very high. Therefore, the description of the product for marketing purposes is not adequate at all and misleads the majority of the customers.

c. Let $R_{l} \leq R \leq R_{h}$. This is the category of moderate risk. The risk of misinforming reflects the existence of two groups of customers. On one hand, the description of the product fits well with one of the groups, but on the other hand, it is unsuitable for the other group of customers and misinforms them. It is obvious, that in order to clarify the features of the product, a revision of the message 
with the description of the product should be made, such that it targets appropriately most of the potential customers. Here the measures of the risk for different categories of tasks may serve to update only the parts of the message, which are mostly misinterpreted.

A survey, aiming to identify the various tasks customers intend to solve for by using the product, can provide useful information in deciding what is the most suitable warranty policy for this product. Of course, the current description of the product, used for advertising and marketing purposes, influences significantly this decision.

\section{Risk of Misinforming and Warranty Policy}

We consider the following three types of warranty contracts:

1. If the product fails within the first three years after the sale, it is replaced or repair free of charge to the customer.

2. If the customer is not fully satisfied with the product within the first three months after the sale, s/he is fully refunded.

3. If the customer is not fully satisfied with the product within the first month after the sale, $\mathrm{s} /$ he is fully refunded and afterwards the product is covered by one-year free repair/replacement warranty.

Next, we discuss how to identify which of the listed above warranties is the most appropriate for customers with different risk levels. We distinguish the following cases:

1. If the level of risk is low, the customers make well-informed purchase decisions. As a result, the first type of warranty is the most appropriate for this type of customers.

2. If the level of risk is high, the second type of warranty seems to be the best, because it will encourage the customers to examine the features of the product for certain period of time and decide whether to keep the product or to inquire full reimbursement.

3. If the level of risk is moderate, the ratio of the number of pessimists to the number of optimists, within the group of buyers, determines the choice of the best warranty. If the optimists are the dominating group, the mixed policy, i.e., the third warranty option, is the best choice, because as much as optimists are open for challenges, they need the option of getting a full refund in the case the product is not suitable for their needs. If the group of pessimists dominates, second warranty option is the best.

\section{Illustrative Example}

\section{Survey}

To illustrate the ideas described in the previous sections, we conducted a survey and collected information needed to evaluate the risk caused by information asymmetry and to analyze its impact on the choice of the product warranty. In Christozov, Chukova, Mateev, (2006), the design of the questionnaire, used for collecting data necessary for the evaluation of the risk of misinforming, did not allow for the study of this risk at a reasonable level of precision. Moreover, the relationship between warranty and risk was left for further study.

In our survey the product $\mathrm{D}$ of interest is a personal computer (PC) with a description given in the Appendix. The current survey is an updated version of the survey in Christozov, Chukova, Mateev, (2006). It consists of two parts. In the first part the respondent is offered a five-level scale to answer the questions related to her/his needs to solve for a particular task and to estimate 
the suitability of the product to solve for this task. This part of the survey, in Christozov, Chukova, Mateev, (2006) was reduced to "yes"/"no" choice. In the second part, information regarding the preferred product warranty is collected. The three warranty policies, as listed earlier in the second section, are offered to choose from to two samples of respondents - the first one are given list of two options and the second sample - all three options.

It seems that the best strategy for any buyer is to purchase the PC with the second type of warranty and after three months, i.e., when the warranty expires, if the PC proves to be suitable for his/her needs, to replace it with a new one with three years free replacement warranty. At the same time, in order to examine whether the computer is suitable for solving for a particular set of tasks, quite a lot of efforts and time have to be invested. For example, several software packages have to be installed and tested, compatibility between different software has to be adjusted, the computer has to be tuned up in order to achieve its best performance, etc. Therefore, in our opinion, it is not reasonable to give up all this time and efforts and start all over again with a new computer in return of only three months extra warranty of malfunctioning.

Three months trial period, which is the second type of warranty, seems a reasonably long period of time to allow the customer to test almost all features of the product that he/she is interested in. For the third warranty option, often one month is not sufficiently long to comprehensively examine the suitability of the product.

The survey was conducted on two independent groups of respondents. The first one was given the choice of the first two types of warranty, while the second group had to choose from all three. This was done in order to observe the affect of the third, mixed, warranty policy on the consumers' choice.

\section{Results of the Survey}

The two forms of the survey are given in the Appendix. In the next section we present a summary of the data and their analysis, followed by recommendations regarding the best choice of the product warranty

\section{Assumptions and default values for the model parameters}

We assume, that the features of the PC, described in the survey, are evaluated by the producer using $p_{i}$ 's for the tasks, listed below. The values of the $p_{i}$ 's are given in the column on the righthand side:

- Using word processing

- Using spreadsheets, (e.g. Excel) $\quad 1.00$

- Using e-mail 0.60

- Surfing Internet $\quad 0.40$

- Solving complicated problems $\quad 1.00$

- Playing Games 0.20

- Watching movies 0.20

- Listening to Music 0.20

As we mentioned earlier, the estimation of the degree of acceptance $q_{i j}$ is still an open problem, that is why, in this study we've assumed that $q_{i j}=q=0.50$ for all tasks and all buyers. Moreover, in order to distinguish between optimists, pessimists and realists, we fixed $\varepsilon=0.05$.

\section{Summary}

Tables 3 and 4 summarize the buyers' and sellers' risk. 
Table 3. Buyers' risk

\begin{tabular}{|l|r|c|c|r|r|r|}
\cline { 2 - 7 } \multicolumn{1}{c|}{} & \multicolumn{3}{c|}{$\begin{array}{c}\text { Survey 1- two forms of war- } \\
\text { ranty }\end{array}$} & \multicolumn{3}{c|}{$\begin{array}{c}\text { Survey 2 - three forms of } \\
\text { warranty }\end{array}$} \\
\hline Category & $\#$ & $\frac{1}{n} \sum_{j=1}^{n} r_{j}^{a}$ & $\frac{1}{n} \sum_{j=1}^{n} r_{j}^{u}$ & $\#$ & $\frac{1}{n} \sum_{j=1}^{n} r_{j}^{a}$ & $\frac{1}{n} \sum_{j=1}^{n} r_{j}^{u}$ \\
\hline Overall & 118 & 0.256 & 0.464 & 54 & 0.296 & 0.492 \\
\hline Optimists & 77 & 0.284 & 0.484 & 38 & 0.337 & 0.541 \\
\hline Pessimists & 16 & 0.249 & 0.433 & 4 & 0.311 & 0.421 \\
\hline Realists & 25 & 0.177 & 0.422 & 12 & 0.159 & 0.361 \\
\hline Warranty 3 months & 13 & 0.224 & 0.465 & 1 & 0.535 & 0.774 \\
\hline Warranty 3 years & 105 & 0.260 & 0.463 & 34 & 0.303 & 0.498 \\
\hline $\begin{array}{l}\text { Warranty 1 month }+1 \\
\text { year }\end{array}$ & & & & 19 & 0.269 & 0.466 \\
\hline
\end{tabular}

Table 4. Seller's risk

\begin{tabular}{|l|c|c|}
\cline { 2 - 3 } \multicolumn{1}{c|}{} & Survey 1 & Survey 2 \\
\hline$R^{s}=$ & 0.463 & 0.488 \\
\hline$R^{u}=$ & 0.450 & 0.488 \\
\hline$R^{a}=$ & 0.252 & 0.298 \\
\hline
\end{tabular}

\section{Interpretation}

As expected, the analysis of the two surveys led to essentially equivalent results, because the surveys were conducted on two samples taken from one and the same population, namely, first-year students in non technologically oriented majors.

The risk for the seller shows to be high enough to deserve attention. For this level of risk, because of domination of optimists, the seller has to offer warranty of the third type. Also, it is clear that a very small proportion of respondents are able to recognize their inability to judge properly the qualities of the product. In the first survey only 13 out 118 have chosen to try the product before making the final solution. In the second survey, 19 out of 54 have chosen the mixed warranty, whereas only one student has expressed preference for the pure trial option. This result shows one's psychological acceptance of the possibility of making a wrong decision and ability to recognize it. For the two surveys, the ratios between optimists, pessimists and realists meet our expectations. Also, we have to keep in mind that this division of the buyers in subgroups of optimists, pessimists and realists dependents on the value of $\varepsilon$.

\section{Conclusion and Future Work}

Studying the risks of misinforming is still in very early stage, but the results obtained so far show that this risk exists and it is significant in indirect trading, which became very popular during the last decade. In addition, designing a feasible warranty policy, as an instrument to enhance the 
trust between parties, requires cost-benefit analyzes based on quantified assessment of the risk of misinforming. In this study, the proposed approach to quantify the risk caused by information asymmetry is mostly practical and it needs further improvement. One of the main directions for our future work will be to adjust the design of the surveys for collecting data for assessing the risk of misinforming, so that we are able to collect appropriate information for the estimation of the buyer's degree of acceptance

\section{References}

Akerlof, G. A. (1970). The market for 'Lemon's: Quality uncertainty and the market mechanism. Quarterly Journal of Economics, 84(3), 488-500.

Arrow, K. (1963). Uncertainty and the welfare economics of medical care. American Economic Review.

Chang-Tseh Hseih, Fujun Lai, and Weihua Shi. (2006). Information orientation and its impact on information asymmetry and e-business adoption: Evidence from China's international trading industry. Industrial Management \& Data Systems, 106(6), 825-840.

Christozov, D., Chukova, S. \& Mateev, P. (2006). A measure of risk caused by information asymmetry in e-commerce. Journal of Issues in Informing Science and Information Technology, 3, 147. Available at http://informingscience.org/proceedings/InSITE2006/IISITChri169.pdf

Christozov, D. (1997). Evaluation of the quality of an option compare to its alternatives. 18th IFIP TC7 Conference on System Modeling and Optimization, Detroit.

Slovac, P. (1993). Perceived risk, trust, and democracy. Risk Analysis, 13, 675-682.

White, M. \& Eiser, R. (2005). Information specificity and hazard risk potential as moderators of trust asymmetry. Risk Analysis, 25(5), DOI. 


\section{Appendix. The Surveys' Forms}

The two surveys have equal first part and different second parts. The first part is presented here only once.

\section{Common part:}

\section{Dear students,}

We are studying the impact of information exchange on business transactions and purchase decisions and the way this exchange affects the customer choice.

We are running the following experiment: Assume that you are offered the opportunity to buy a personal computer (PC) at a highly attractive price (say, the sale price is $20 \%$ less than you would expect to pay).

\section{The product information is given as follows:}

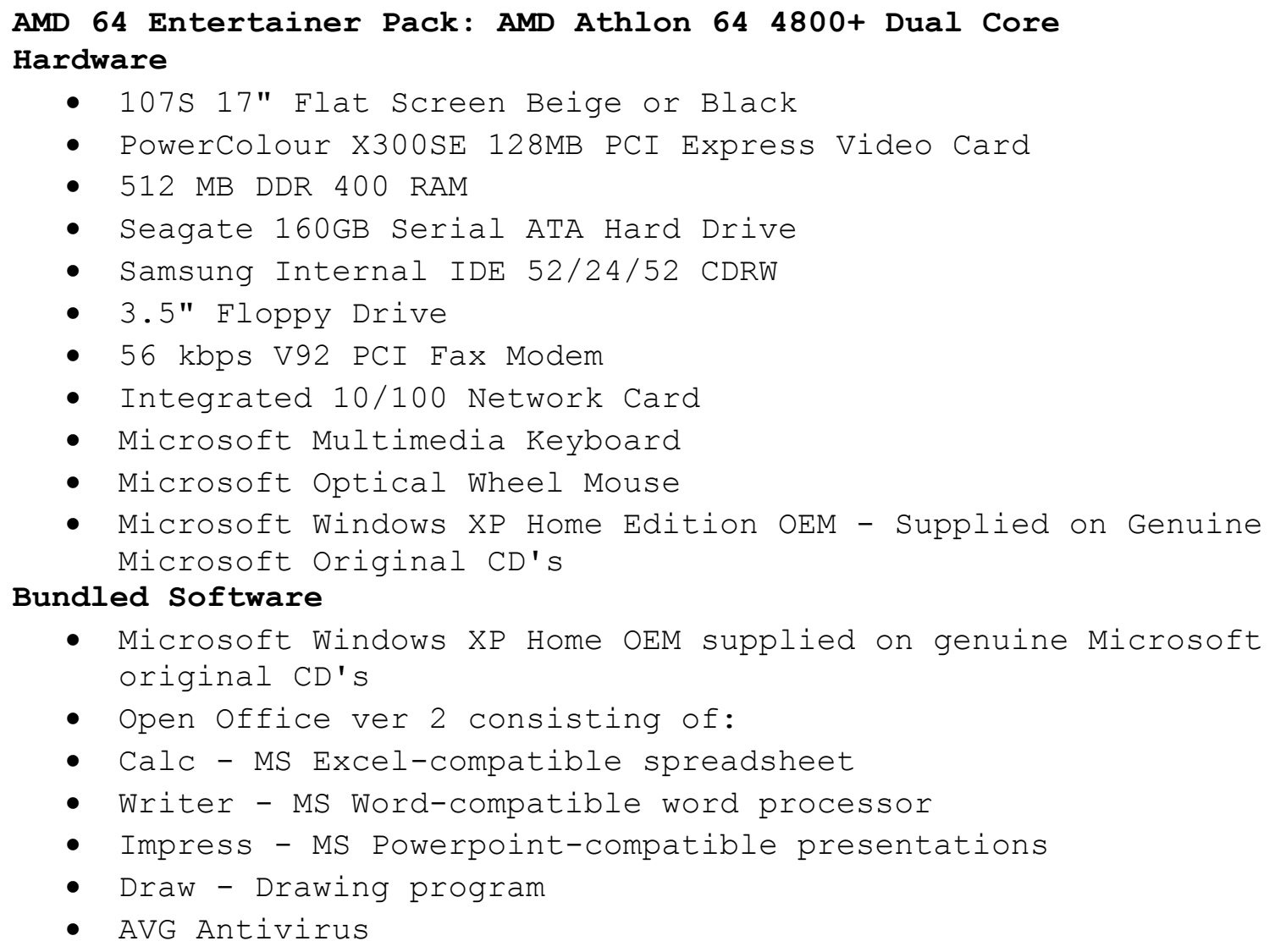

- Microsoft Windows XP Home OEM supplied on genuine Microsoft original CD's

- Open Office ver 2 consisting of:

- Calc - MS Excel-compatible spreadsheet

- Writer - MS Word-compatible word processor

- Impress - MS Powerpoint-compatible presentations

- Draw - Drawing program

- AVG Antivirus

We need your input on the following:

1. Please fill in the table below by ticking the box that best represents your needs in order to perform the stated task (listed in the first column) and your opinion on the extent to which the offered computer is capable of satisfying them. 


\begin{tabular}{|c|c|c|c|c|c|c|c|c|c|c|c|c|}
\hline \multirow{3}{*}{$\mathbf{T z}$} & \multicolumn{6}{|c|}{ Degree of your needs } & \multicolumn{6}{|c|}{ The PC degree of capability } \\
\hline & \multicolumn{6}{|c|}{ Low .............High } & \multicolumn{6}{|c|}{ Low .....................High } \\
\hline & 0 & 1 & 2 & 3 & 4 & 5 & 0 & 1 & 2 & 3 & 4 & 5 \\
\hline Using word proces & & & & & & & & & & & & \\
\hline Using spreadsheets & & & & & & & & & & & & \\
\hline Using e-mail & & & & & & & & & & & & \\
\hline Surfing Internet & & & & & & & & & & & & \\
\hline Solving complicate & & & & & & & & & & & & \\
\hline Playing Games & & & & & & & & & & & & \\
\hline Watching movies & & & & & & & & & & & & \\
\hline Listening to Music & & & & & & & & & & & & \\
\hline
\end{tabular}

\section{Specific part: Survey 1}

Which warranty option would you prefer for your purchase? Please, choose ONE of the options listed below, by ticking the box on the right:

\begin{tabular}{|l|l|}
\hline $\begin{array}{l}\text { The PC is replaced or repaired free of charge to the customer if it fails within the } \\
\text { first THREE years after the sale date. }\end{array}$ & \\
\hline $\begin{array}{l}\text { The customer will get full refund if he/she is not fully satisfied with the PC within } \\
\text { the first THREE months after the sale date. }\end{array}$ & $\square$ \\
\hline
\end{tabular}

\section{Specific part: Survey 1}

Which warranty option would you prefer for your purchase? Please, choose ONE of the options listed below, by ticking the box on the right:

\begin{tabular}{l} 
The PC is replaced or repaired free of charge to the customer if it fails within the \\
first THREE years after the sale date. \\
\hline $\begin{array}{l}\text { The customer will get full refund if he/she is not fully satisfied with the PC within } \\
\text { the first THREE months after the sale date. }\end{array}$ \\
$\begin{array}{l}\text { The customer will get full refund if he/she is not fully satisfied with the PC within } \\
\text { the FIRST month after purchasing AND } \\
\text { the PC is replaced or repaired free of charge to the customer if it fails within ONE } \\
\text { year after the sale date. }\end{array}$
\end{tabular}




\section{Biography}

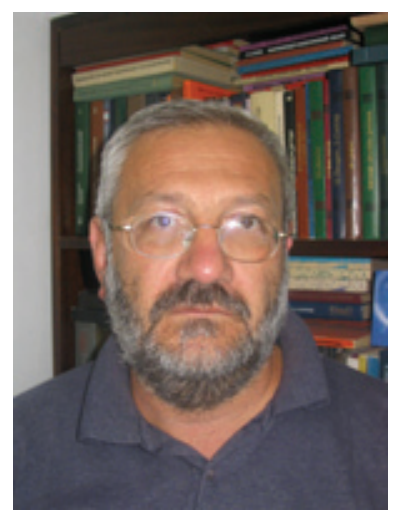

Dimitar Christozov is a Professor of Computer Science at the American University in Bulgaria, Blagoevgrad 2700, Bulgaria since 1993. He has more than 25 years of experience in areas as computer science, quality management and information systems. He graduated Mathematics from Sofia University "St. Kliment Ohridski" in 1979. He completed his PhD thesis "Computer Aided Evaluation of Machine Reliability" in 1986. In ICTT "Informa" (1986-1993) Dr. Christozov was involved in establishing the national information network for technology transfer and research in the areas of technologies assessment, integral quality measures and information systems for quality management. In these areas he was recognized as one of the leading experts in Bulgaria. Professor Christozov has more than 50 publications as separate volume, journal papers and papers in refereed procideengs. He is a founding member of Informing Science Institute and chair of Bulgarian Informing Science Society; and member of the Bulgarian Statisyical Society.

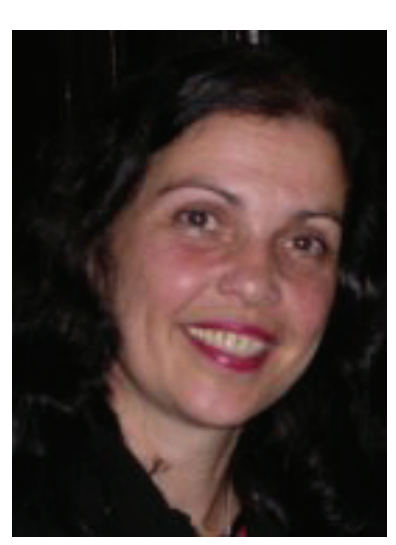

Dr. Stefanka Chukova is a Reader in Statistics and Operations Research at the School of Mathematics, Statistics and Computer Science, Victoria University of Wellington, Private Bag 600, Wellington, New Zealand, e-mail: schukova@mcs.vuw.ac.nz. She has a PhD and MSc in Mathematics (concentration in Probability and Statistics) and BSc in Mathematics from University of Sofia, Sofia, Bulgaria. Her research interests are in applied stochastic models, warranty analysis, reliability and queueing. She has more than 50 publications and has presented papers at national and international conferences and workshops. She is a member of ORSNZ, AWIS and ASA.

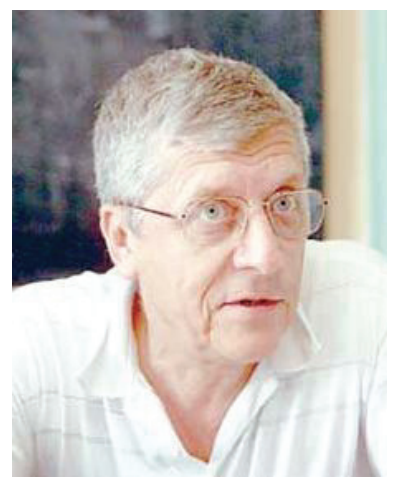

Dr. Plamen S. Mateev is Associate professor in Faculty of Mathematics and Informatics, Sofia University "St.Kliment Ohridski", Department "Probability, Operation research, Statistics", Bulgaria, 1164 Sofia, 5, J.Boucher str., e-mail: pmat at fmi.uni-sofia.bg.

His MSc in Mathematical Statistics is from Sofia University and his $\mathrm{PhD}$ is from Moscow State University. The research interests are in communication theory, applied statistics, statistical software and applications. More than 70 papers are published in scientific journals and proceedings of scientific conferences. He is a member of Bulgarian Statistical Society, ENBIS and Bulgarian Informing Science Society 